\title{
Chronic cough and obstructive sleep apnoea in a sleep laboratory-based pulmonary practice
}

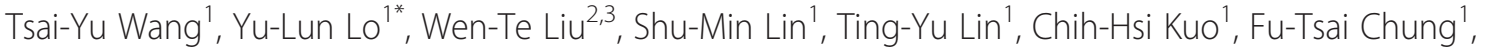 \\ Pai-Chien Chou', Po-Jui Chang ${ }^{1}$, Yung-Lun $\mathrm{Ni}^{4}$, Shu-Chuan Ho ${ }^{1,3}$, Horng-Chyuan Lin ${ }^{1}$, Chun-Hua Wang ${ }^{1}$, \\ Chih-Teng $\mathrm{Yu}^{1}$ and Han-Pin Kuo ${ }^{1}$
}

\begin{abstract}
Background: Obstructive sleep apnoea (OSA) has recently been identified as a possible aetiology for chronic cough. The aim of this study was to compare the incidence of chronic cough between patients with and without OSA and the impact of continuous positive airway pressure (CPAP) treatment in resolving chronic cough.

Methods: Patients referred to the sleep laboratory from January 2012 to June 2012 were retrospectively enrolled. Clinical data, treatment course and resolution of chronic cough were analysed. Specifically, gastro-oesophageal reflux (GERD), upper airway cough syndrome, asthma, apnoea-hypopnoea index and the impact of CPAP treatment on chronic cough were assessed.

Results: A total of 131 patients were reviewed. The incidence of chronic cough in the OSA group was significantly higher than the non-OSA group (39/99 (39.4\%) vs. 4/32 (12.5\%), $p=0.005)$. Both GERD and apnoea-hypopnoea index were significantly associated with chronic cough in univariate analysis. After multivariate logistic regression, GERD was the only independent factor for chronic cough. Moreover, the resolution of chronic cough was more significant in the OSA patients with CPAP treatment compared with those not receiving CPAP treatment (12/18 (66.7\%) vs. 2/21 (9.5\%), $p=0.010)$
\end{abstract}

Conclusion: The incidence of chronic cough was significantly higher in the OSA patients. In addition, CPAP treatment significantly improved chronic cough. Therefore, OSA may be a contributory factor to chronic cough.

Keywords: Chronic cough, Obstructive sleep apnoea, Continuous positive airway pressure

\section{Introduction}

The incidence of chronic cough ranges from $9 \%$ to $33 \%$ of the adult population [1,2]. The most common aetiologies for chronic cough in non-smokers are upper airway cough syndrome (UACS), gastro-oesophageal reflux (GERD) and asthma, all of which are empirically treated $[2,3]$. However, the aetiologies of $12 \%$ to $42 \%$ of coughs are unexplained despite thorough evaluation [4]. Therefore, it is important to explore other possible aetiologies for chronic cough. A recent study reported four patients with unexplained chronic cough who were found to have obstructive sleep apnoea (OSA). Moreover, a prospective

\footnotetext{
* Correspondence: loyulun@hotmail.com

'Department of Thoracic Medicine, Chang Gung Memorial Hospital and Chang Gung University, School of Medicine, 199 Tun-Hwa N. Rd., Taipei, Taiwan

Full list of author information is available at the end of the article
}

study also reported that of 108 patients being referred to sleep clinics for sleep disordered breathing, 33\% had a co-existing cough [5], which suggests an association between chronic cough and OSA. In addition, another study reported that $44 \%$ of patients with chronic cough had OSA, 93\% of whom demonstrated a significant improvement in cough with continuous positive airway pressure (CPAP) treatment [6]. The mechanism between chronic cough and OSA is still not clear, although GERD, UACS and airway inflammation have been proposed to be involved [7]. However, studies on these topics have lacked an adequate control group or included a small sample size [5-7]. Therefore, the aim of this study was to evaluate the prevalence of chronic cough and the associated factors in patients with OSA, and the effect of CPAP treatment.

\section{Biomed Central}

(c) 2013 Wang et al.; licensee BioMed Central Ltd. This is an open access article distributed under the terms of the Creative Commons Attribution License (http://creativecommons.org/licenses/by/2.0), which permits unrestricted use, distribution, and reproduction in any medium, provided the original work is properly cited. 


\section{Materials and methods Study population}

We retrospectively recruited patients with suspected OSA who were referred to our sleep lab by thoracic doctors from January 2012 to June 2012 in Chang Gung Memorial Hospital, a tertiary hospital in Taiwan. Patients were excluded if they were smokers, or if they had had an acute upper airway infection in the past 4 weeks, abnormal chest X-rays or any history of malignancy. The Chang Gung Medical Foundation Institutional Review Board approved this study (102-2103B) and waived the requirement for informed consent due to the retrospective nature of the study.

\section{Study design}

The medical records of each patient were reviewed to collect the clinical characteristics and laboratory results. In addition, data on comorbidities, aetiologies for the chronic cough such as GERD, UACS and asthma, medications, pulmonary function, Epworth sleepiness scale and clinical follow-up for 3 months after CPAP treatment were analysed. The improvements in cough are decided according to patients' self-report during following visits.

\section{Definitions}

A chronic cough was defined as a cough lasting for 2 months or more. Upper airway cough syndrome was defined as: (1) patients describing the sensation of "having something drip down into their throat" and/or the need to frequently clear their throat; (2) computed tomographic imaging or Water's view showing chronic sinusitis, or a positive finding by nasopharyngoscopy; (3) response to intranasal corticosteroids or anti-histamines [8,9]. Asthma was defined as a positive result of provocation test or PEF variability rate $>20 \%[8]$. GERD was defined as a response to anti-GERD medication [8], or if 24-h pH level exceeded the 95th percentile for percentage total time with a $\mathrm{pH}<4$ of $>4.8 \%$ [9]. Sleep stages and arousals were scored according to the AASM criteria [10]. Established criteria were used to score respiratory events such as hypopnea, obstructive apnoea, central apnoea, mixed type apnoea, and Cheyne-Stokes respiration [11]. Apnoea was defined as oronasal flow cessation for more than 10 seconds. Hypopnea was defined as a $50 \%$ reduction in oronasal flow for more than 10 seconds or a $30 \%$ reduction followed by arousal or more than 3\% decrease in $\mathrm{SaO} 2$. Based on the polysomnography results, OSA was defined as an apnoea/ hypopnea index $(\mathrm{AHI})>15$ per hour, of which $\geq 50 \%$ were obstructive. CPAP titration to determine the optimal pressure was performed according to standard guidelines [12].

\section{Statistical analysis}

Data were expressed as mean \pm SD (standard deviation) or mean \pm SEM (standard error of the mean). The Student's $t$ test was used for comparisons of continuous variables between the two groups, while the Mann-Whitney test was used for non-normal distributions. Categorical variables were compared by chi-square or Fisher's exact tests. The Pearson product correlation coefficient was used to examine correlations between variables and chronic cough. Multivariate logistic regression analysis was used to determine the independent factors associated with chronic cough. A p value less than 0.05 was considered to be statistically significant. All analyses were performed using the SPSS software package version 13.0 (SPSS Inc., Chicago, IL, USA).

\section{Results}

Demographic and clinical characteristics of the patients

A total of 147 patients with suspected OSA were identified at our sleep lab between January 2012 and June 2012, 30 of whom were excluded due to the following reasons: $8(5.4 \%)$ were current smokers; $5(3.4 \%)$ had had acute upper airway infections in the past 4 weeks; 2 (1.4\%) had abnormal chest X-rays, and 1 (0.7\%) had a malignancy. The records of the remaining 131 patients were further reviewed, of whom 99 had OSA and 32 did not. The baseline demographic data and clinical characteristics of these patients are listed in Table 1 . The mean ages of the patients with and without OSA were similar (52.2 and 48.3 years, respectively). The mean AHI in the OSA group was $53.6 \pm 24.7 / \mathrm{h}$ of sleep, indicating that most of the patients had severe OSA, accompanied with a higher percentage of males (75.8\%) and higher BMI $(28.9 \pm 4.1$ vs. $24.9 \pm 4.3)$ compared with the Non-OSA group. Moreover, the percentage of chronic cough was significantly higher in the OSA group compared to the Non-OSA group ( $39.4 \%$ vs. $12.5 \%, \mathrm{p}=0.005)$. Interestingly, the incidence of GERD was also significantly higher in the OSA group, while the incidence of UACS and asthma was similar between the two groups. Other characteristics including Epworth sleepiness scale, pulmonary function, and medications including nasal steroids, anti-histamines, angiotensin converting enzyme inhibitors, angiotensin receptor blockers, inhaled corticosteroids and long-acting $\beta_{2}$ agonists were also similar between the two groups.

Univariate and multivariate logistic regression analysis for the variables associated with chronic cough

In univariate analysis, AHI was significantly correlated with chronic cough (Table 2). GERD was also significantly correlated with chronic cough, while UACS, asthma and BMI were not significantly correlated with chronic cough. AHI, UACS, GERD and asthma were then used in the multivariate logistic regression model, which showed that GERD was the only independent factor associated with chronic cough (Table 3). 
Table 1 Subjects demonstration

\begin{tabular}{|c|c|c|c|}
\hline Characteristics & $\begin{array}{c}\text { OSA } \\
n=99\end{array}$ & $\begin{array}{c}\text { Non-OSA } \\
n=32\end{array}$ & $p$-value \\
\hline Age & $52.2 \pm 11.6$ & $48.3 \pm 13.1$ & 0.105 \\
\hline Male, n (\%) & $75(75.8)$ & $17(53.1)$ & 0.025 \\
\hline BMI & $28.9 \pm 4.1$ & $24.9 \pm 4.3$ & 0.000 \\
\hline Epworth Sleepiness Scale & $12.9 \pm 4.5$ & $12.8 \pm 5.5$ & 0.884 \\
\hline Total AHI, /h & $53.6 \pm 24.7$ & $10.1 \pm 4.3$ & 0.000 \\
\hline \multicolumn{4}{|l|}{ Pulmonary function test } \\
\hline $\mathrm{FEV}_{1} / \mathrm{FVC}$ & $83.7 \pm 8.4$ & $82 \pm 12.5$ & 0.394 \\
\hline $\mathrm{FEV}_{1}$ (\% predicted) & $82.6 \pm 20.1$ & $82.6 \pm 17.5$ & 0.993 \\
\hline FVC (\% predicted) & $82.4 \pm 17.9$ & $86.8 \pm 22.3$ & 0.278 \\
\hline Chronic cough & 39 (39.4) & $4(12.5)$ & 0.005 \\
\hline Upper airway cough syndrome & 79 (79.8) & $23(71.9)$ & 0.340 \\
\hline Gastro-esophageal reflux disease & $43(43.4)$ & $5(15.6)$ & 0.006 \\
\hline Asthma & $18(18.2)$ & $5(15.6)$ & 1.000 \\
\hline \multicolumn{4}{|l|}{ Medication } \\
\hline Nasal steroid & $72(72.7)$ & $20(62.5)$ & 0.276 \\
\hline Anti-histamine & $79(79.8)$ & $23(71.9)$ & 0.340 \\
\hline ACEl or ARB & $11(11.1)$ & $0(0.0)$ & 0.065 \\
\hline Inhaled corticosteroid & $18(18.2)$ & $5(15.6)$ & 1.000 \\
\hline Long-acting $\beta_{2}$ agonist & $4(4.0)$ & $2(6.2)$ & 0.634 \\
\hline Proton pump inhibitor & $43(43.4)$ & $5(15.6)$ & 0.006 \\
\hline
\end{tabular}

Data are presented as mean $\pm \mathrm{SD}$; $B M I$ body mass index, FEV1 forced expiratory volume in one second, FVC forced volume capacity, ACEI angiotensin converting enzyme inhibitor, $A R B$ angiotensin receptor blocker.

Cough response to CPAP treatment in the patients with OSA and chronic cough

A total of 39 patients with both OSA and chronic cough were identified, of whom $18(46.2 \%)$ received CPAP treatment for 3 months (Table 4). A significant improvement in the chronic cough was noted in the patients who received CPAP treatment compared to those who did not receive CPAP treatment (12/18 (66.7\%) vs. $2 / 21$ (9.5\%), $\mathrm{p}=0.010)$. In addition, CPAP treatment was also

Table 2 Univariate analysis of the variables associated with chronic cough

\begin{tabular}{|c|c|c|c|c|}
\hline Parameter & beta & $\begin{array}{l}\text { Standard } \\
\text { error }\end{array}$ & $95 \% \mathrm{Cl}$ & $P$ value \\
\hline BMI & 0.060 & 0.042 & 0.98 to 1.15 & 0.153 \\
\hline Male & -0.033 & 0.406 & 0.437 to 2.15 & 0.936 \\
\hline $\mathrm{AHI}$ & 0.016 & 0.007 & 1.00 to 1.03 & 0.019 \\
\hline GERD & 2.379 & 0.434 & 4.61 to 25.27 & 0.000 \\
\hline $\begin{array}{l}\text { Upper airway cough } \\
\text { syndrome }\end{array}$ & 0.539 & 0.481 & 0.67 to 4.40 & 0.262 \\
\hline Asthma & 0.778 & 0.468 & 0.87 to 5.44 & 0.096 \\
\hline FEV1 (\%) & -0.005 & 0.010 & 0.98 to 1.02 & 0.650 \\
\hline
\end{tabular}

$B M I$ body mass index, $A H I$ apnoea-hypopnoea index, GERD Gastro-oesophageal reflux disease, FEV1 forced expiratory volume in one second.
Table 3 Multivariate analysis with logistic regression: factors associated with chronic cough

\begin{tabular}{lcccc}
\hline Factors & beta & SE & P value & OR \\
\hline AHI & 0.009 & 0.008 & 0.245 & 1.009 \\
Upper airway cough & 0.291 & 0.556 & 0.601 & 1.337 \\
syndrome & & & & \\
GERD & 2.339 & 0.453 & 0.000 & 10.373 \\
Asthma & 0.884 & 0.554 & 0.110 & 2.422 \\
\hline AHI apnoea-hypopnoea index, GERD Gastro-oesophageal reflux disease.
\end{tabular}

beneficial for the patients with both OSA and asthma, whose chronic cough was significantly improved by CPAP treatment compared to those who did not receive CPAP treatment $(3 / 4(75 \%)$ vs. $1 / 7(14.3 \%), p=0.044)$. Similar results were also found in UACS and GERD (2/18 (11.1\%) vs. $10 / 14$ (71.4\%), $\mathrm{p}=0.001$; and $1 / 15$ (6.7\%) vs. $8 / 14$ (57.1\%), $\mathrm{p}=0.005$, respectively).

\section{Discussion}

This study demonstrated that the prevalence of chronic cough was significantly higher in the OSA group. In univariate analysis, AHI and GERD were significantly associated with chronic cough. In multivariate analysis, GERD was the only factor associated with chronic cough, which

Table 4 Comparison of the OSA patients with chronic cough who did and did not receive CPAP treatment

\begin{tabular}{lccc}
\hline Characteristics & $\begin{array}{c}\text { OSA with CPAP } \\
\text { treatment } \\
\mathbf{n}=\mathbf{1 8}\end{array}$ & $\begin{array}{c}\text { OSA without } \\
\text { CPAP treatment }\end{array}$ & $\boldsymbol{p}$-value \\
$\mathbf{n}=\mathbf{2 1}$ & \\
\hline Age & $49.8 \pm 9.5$ & $57.1 \pm 10.8$ & 0.055 \\
Male, n (\%) & $16(88.9)$ & $14(66.7)$ & 0.139 \\
BMl & $29.2 \pm 5.4$ & $29.1 \pm 3.4$ & 0.602
\end{tabular}

Pulmonary function

test

$\mathrm{FEV}_{1} / \mathrm{FVC}$

$\mathrm{FEV}_{1}$ (\% predicted)

$78.9 \pm 12.5 \quad 85.3 \pm 6.0 \quad 0.193$

FVC (\% predicted)

$76.6 \pm 23.5 \quad 85.4 \pm 16.8 \quad 0.317$

Epworth Sleepiness

$79.4 \pm 19.5 \quad 86.2 \pm 16.6 \quad 0.367$

Scale

$12.9 \pm 4.1 \quad 13.4 \pm 5.3 \quad 0.618$

$\begin{array}{llll}\text { Upper airway cough } & 18(85.7) & 14(77.8) & 0.682\end{array}$

syndrome

$\begin{array}{llll}\text { Gastro-esophageal } & 14(77.8) & 15(71.4) & 0.726\end{array}$

reflux disease

Asthma

$4(22.2) \quad 7(33.3) \quad 0.497$

Sleep parameters

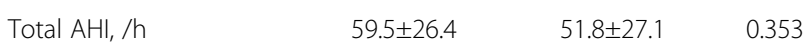

$\begin{array}{llll}\text { CPAP titration pressure } & 8.8 \pm 3.0 & 7.3 \pm 1.8 & 0.318\end{array}$

$\begin{array}{llll}\text { Improved cough, } \mathbf{n}(\%) & 12(66.7) & 2(9.5) & 0.010\end{array}$

Data are presented as mean \pm SEM.

$B M I$ body mass index, FEV 1 forced expiratory volume in one second, FVC forced volume capacity, $A H I$ apnoea-hypopnoea index. 
was significantly improved after CPAP treatment. To the best of our knowledge, this is the first study to report an association between chronic cough and OSA.

The most common etiologies of chronic cough are GERD, rhinosinusitis, and asthma [13]. Recently, several reports have suggested an association between chronic cough and obstructive apnoea [5-7]. Chan et al. reported that the prevalence rate of chronic cough in OSA patients is up to $33 \%$ [5], which is much higher than that in the general population $[14,15]$. In Chan et al's study [5], both GERD and rhinitis played important roles in chronic cough, however, there was no control group and the number of cases was relatively small. In the present study, the prevalence of chronic cough in the patients with OSA was $38.6 \%$, which is similar to the results of Chan et al. [5]. In addition, the number of cases in the present study was larger, and most importantly, the present study enrolled a control group. Compared to the control group, the incidence of chronic cough was significantly higher in the OSA group. Interestingly, the incidence of GERD was also significantly higher in the OSA group, but not UACS or asthma.

GERD is known to be an important aetiology of chronic cough, and a higher prevalence of GERD is expected in patients with OSA due to large intrathoracic negative pressure swings during apnoea episodes aggravating the severity of GERD [16]. Several sleep lab-based studies have reported incidence rates of GERD in OSA patients ranging from $64.7 \%$ to $100 \%$ [17-19]. In a large cross-section epidemiology study, subjects with nocturnal GERD had a significantly higher incidence of OSA than those without nocturnal GERD (16\% vs. $5 \%)$. Nasal CPAP has been shown to reduce GERD in patients with OSA $[19,20]$, suggesting a strong relationship between GERD and OSA. In the present study, only AHI and GERD were associated with chronic cough in univariate analysis, and only GERD was associated with chronic cough in multivariate analysis. This implies that GERD may be the most important aetiology of chronic cough in patients with OSA. However, the present study is a retrospective study, and further large-scale prospective studies are needed to draw a more definitive conclusion.

Nasal obstruction is also associated with OSA, and possible mechanisms such as the Starling resistor model, unstable oral breathing, nasal-ventilatory reflex and nitric oxide have been identified [21]. In the Wisconsin Sleep Study, subjects with self-reported nocturnal nasal congestion had a three-fold increase in the incidence of snoring [22]. On the other hand, a prospective study reported that allergic rhinitis is directly associated with OSA [23]. The use of nasal steroids has been reported to improve sleep quality, but not the severity in patients with severe OSA [24] or in those who receive nasal surgery [25]. Therefore, it is reasonable to assume nasal steroids or surgery does not improve chronic cough, which is related to OSA. In the present study, a high percentage of rhinosinusitis was noted in the OSA patients, and most of them were treated with nasal steroids and anti-histamines while only some with nasal surgery. Further, rhinosinusitis was not associated with chronic cough in the present study.

The incidence of asthma in patients with chronic cough has been reported to range from $16 \%$ to $41.8 \%$, and coughing has been reported to be significantly improved by inhaled corticosteroid treatment [26]. However, a significantly higher dose of inhaled corticosteroids is needed to control asthma when sputum coexists with eosinophils and neutrophils [27]. Moreover, neutrophils are activated and delay apoptosis $[28,29]$ during the process of ische$\mathrm{mia} /$ reperfusion caused by OSA. Therefore, OSA is an important factor in aggravating asthma control, which can be reversed by CPAP treatment [30]. In addition, the asthma-related chronic cough, which is aggravated by OSA, can also be improved by CPAP. In the present study, chronic cough was significantly improved in the patients with both OSA and asthma by CPAP treatment compared to those who did not receive CPAP treatment (3/4 (75\%) vs. $1 / 7(14.3 \%) ; \mathrm{p}=0.044)$. However, asthma was not an independent factor contributing to chronic cough in this study, and the number of case was relatively small. Further large-scale studies are needed to clarify this issue.

The major limitations of the present study are its retrospective nature, which may have led to bias in patient selection. Second, the sample size of the study is small, and therefore the results of the study should be interpreted with caution. A prospective study with a larger sample size is warranted to further confirm the results. Finally, the population in this study was based in a sleep lab, so extrapolation of the results to the general population should be done with caution.

\section{Conclusions}

In conclusion, the incidence of chronic cough was significantly higher in the patients with OSA. Both GERD and AHI were significantly associated with chronic cough in univariate analysis, however GERD was the only independent factor associated with chronic cough in multivariate analysis. Chronic cough was significantly improved after CPAP treatment for the patients with OSA, and therefore OSA may be a contributory factor to chronic cough.

\section{Abbreviations}

BMI: Body mass index; FEV1: Forced expiratory volume in one second;

FVC: Forced volume capacity; ACEl: Angiotensin converting enzyme inhibitor; ARB: Angiotensin receptor blocker; AHI: Apnoea-hypopnoea index;

GERD: Gastro-oesophageal reflux disease; FEV1: Forced expiratory volume in one second; CPAP: Continuous positive airway pressure; UACS: Upper airway cough syndrome. 


\section{Competing interests}

The authors declare that they do not have any financial competing interests in relation to the current manuscript.

\section{Authors' contributions}

T-YW contributed to conceptualization and design of this study; collection, analysis, and interpretation of the data; and preparation of the manuscript. Y-LL contributed to conceptualization and design of this study; collection, analysis, and interpretation of the data; and preparation of the manuscript. T-YW, Y-LL, W-TL, S-ML, T-YL, C-HK, F-TC, P-CC, P-JC, Y-LN, S-CH, H-CL, C-HW, $\mathrm{C}-\mathrm{TY}$ contributed to collection, analysis, and interpretation of the data and preparation of the manuscript. H-PK contributed to conceptualization and design of the study; collection and interpretation of the data; and preparation of the manuscript. All authors read and approved the final manuscript.

\section{Author details}

${ }^{1}$ Department of Thoracic Medicine, Chang Gung Memorial Hospital and Chang Gung University, School of Medicine, 199 Tun-Hwa N. Rd., Taipei, Taiwan. ${ }^{2}$ Division of Pulmonary, Department of Internal Medicine, Shuang Ho Hospital, Taipei, Taiwan. ${ }^{3}$ School of Respiratory Therapy, College of Medicine, Taipei Medical University, Taipei, Taiwan. ${ }^{4}$ Department of Chest Medicine, Buddhist Tzu Chi General Hospital, Taichung Branch, Taichung, Taiwan.

Received: 3 August 2013 Accepted: 28 October 2013

Published: 5 November 2013

\section{References}

1. Chung KF, Pavord ID: Prevalence, pathogenesis, and causes of chronic cough. Lancet 2008, 371:1364-1374.

2. Morice A: Chronic cough: epidemiology. Chron Respir Dis 2008, 5:43-47.

3. Pratter MR, Brightling CE, Boulet LP, Irwin RS: An empiric integrative approach to the management of cough: ACCP evidence-based clinical practice guidelines. Chest 2006, 129:222S-231S.

4. McGarvey LP: Idiopathic chronic cough: a real disease or a failure of diagnosis? Cough 2005, 1:9.

5. Chan KK, Ing AJ, Laks L, Cossa G, Rogers P, Birring SS: Chronic cough in patients with sleep-disordered breathing. Eur Respir J 2010, 35:368-372.

6. Sundar KM, Daly SE, Pearce MJ, Alward WT: Chronic cough and obstructive sleep apnea in a community-based pulmonary practice. Cough 2010, 6:2.

7. Birring SS, Ing AJ, Chan K, Cossa G, Matos S, Morgan MD, Pavord ID: Obstructive sleep apnoea: a cause of chronic cough. Cough 2007, 3:7.

8. Lai K, Chen R, Lin J, Huang K, Shen H, Kong L, Zhou X, Luo Z, Yang L, Wen $F$, Zhong N: A prospective, multicenter survey on causes of chronic cough in China. Chest 2013, 143:613-620.

9. McGarvey LP, Heaney LG, Lawson JT, Johnston BT, Scally CM, Ennis M, Shepherd DR, MacMahon J: Evaluation and outcome of patients with chronic non-productive cough using a comprehensive diagnostic protocol. Thorax 1998, 53:738-743.

10. EEG arousals: scoring rules and examples: a preliminary report from the Sleep Disorders Atlas Task Force of the American Sleep Disorders Association. Sleep 1992, 15:173-184.

11. Sleep-related breathing disorders in adults: recommendations for syndrome definition and measurement techniques in clinical research. The Report of an American Academy of Sleep Medicine Task Force. Sleep 1999, 22:667-689.

12. Kushida CA, Chediak A, Berry RB, Brown LK, Gozal D, Iber C, Parthasarathy S, Quan SF, Rowley JA: Clinical guidelines for the manual titration of positive airway pressure in patients with obstructive sleep apnea. J Clin Sleep Med 2008, 4:157-171.

13. Birring SS: Controversies in the evaluation and management of chronic cough. Am J Respir Crit Care Med 2011, 183:708-715.

14. Di Pede C, Viegi G, Quackenboss JJ, Boyer-Pfersdorf P, Lebowitz MD: Respiratory symptoms and risk factors in an Arizona population sample of Anglo and Mexican-American whites. Chest 1991, 99:916-922.

15. Voll-Aanerud M, Eagan TM, Wentzel-Larsen T, Gulsvik A, Bakke PS: Changes in respiratory symptoms and health-related quality of life. Chest 2007, 131:1890-1897.

16. Ing AJ, Ngu MC, Breslin AB: Obstructive sleep apnea and gastroesophageal reflux. Am J Med 2000, 108(Suppl 4a):120S-125S.
17. Graf Kl, Karaus M, Heinemann S, Korber S, Dorow P, Hampel KE: Gastroesophageal reflux in patients with sleep apnea syndrome. Z Gastroenterol 1995, 33:689-693.

18. Penzel T, Becker HF, Brandenburg U, Labunski T, Pankow W, Peter JH: Arousal in patients with gastro-oesophageal reflux and sleep apnoea. Eur Respir J 1999, 14:1266-1270.

19. Kerr P, Shoenut JP, Millar T, Buckle P, Kryger MH: Nasal CPAP reduces gastroesophageal reflux in obstructive sleep apnea syndrome. Chest 1992, 101:1539-1544.

20. Green BT, Broughton WA, O'Connor JB: Marked improvement in nocturnal gastroesophageal reflux in a large cohort of patients with obstructive sleep apnea treated with continuous positive airway pressure. Arch Intern Med 2003, 163:41-45.

21. Georgalas C: The role of the nose in snoring and obstructive sleep apnoea: an update. Eur Arch Otorhinolaryngol 2011, 268:1365-1373.

22. Young T, Finn L, Palta M: Chronic nasal congestion at night is a risk factor for snoring in a population-based cohort study. Arch Intern Med 2001, 161:1514-1519.

23. McNicholas WT, Tarlo S, Cole P, Zamel N, Rutherford R, Griffin D, Phillipson EA: Obstructive apneas during sleep in patients with seasonal allergic rhinitis. Am Rev Respir Dis 1982, 126:625-628.

24. Craig TJ, Hanks CD, Fisher LH: How do topical nasal corticosteroids improve sleep and daytime somnolence in allergic rhinitis? J Allergy Clin Immunol 2005, 116:1264-1266.

25. Li HY, Lee LA, Wang PC, Chen NH, Lin Y, Fang TJ: Nasal surgery for snoring in patients with obstructive sleep apnea. Laryngoscope 2008, 118:354-359.

26. Abouzgheib W, Pratter MR, Bartter T: Cough and asthma. Curr Opin Pulm Med 2007, 13:44-48.

27. Matsuoka H, Niimi A, Matsumoto H, Takemura M, Ueda T, Yamaguchi M, Jinnai M, Inoue $H$, Ito I, Chin K, Mishima M: Inflammatory subtypes in cough-variant asthma: association with maintenance doses of inhaled corticosteroids. Chest 2010, 138:1418-1425.

28. Schulz R, Mahmoudi S, Hattar K, Sibelius U, Olschewski H, Mayer K, Seeger W, Grimminger F: Enhanced release of superoxide from polymorphonuclear neutrophils in obstructive sleep apnea. Impact of continuous positive airway pressure therapy. Am J Respir Crit Care Med 2000, 162:566-570.

29. Dyugovskaya L, Polyakov A, Lavie P, Lavie L: Delayed neutrophil apoptosis in patients with sleep apnea. Am J Respir Crit Care Med 2008, 177:544-554.

30. Lafond C, Series F, Lemiere C: Impact of CPAP on asthmatic patients with obstructive sleep apnoea. Eur Respir J 2007, 29:307-311.

\section{doi:10.1186/1745-9974-9-24}

Cite this article as: Wang et al:: Chronic cough and obstructive sleep apnoea in a sleep laboratory-based pulmonary practice. Cough 2013 9:24.

\section{Submit your next manuscript to BioMed Central and take full advantage of:}

- Convenient online submission

- Thorough peer review

- No space constraints or color figure charges

- Immediate publication on acceptance

- Inclusion in PubMed, CAS, Scopus and Google Scholar

- Research which is freely available for redistribution 